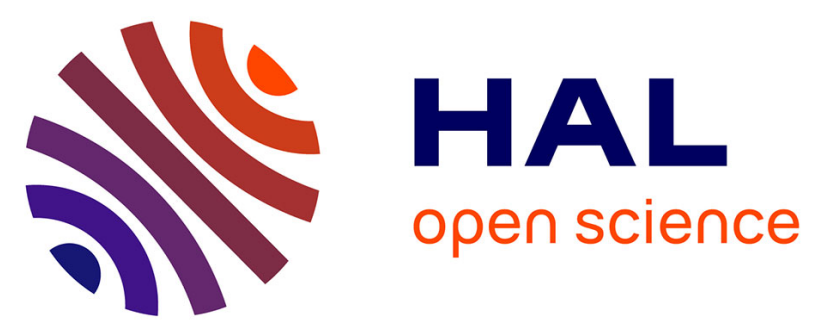

\title{
Investigation of the martensitic transformation and the damping behavior of a superelastic $\mathrm{Ti}-\mathrm{Ta}-\mathrm{Nb}$ alloy
}

Emmanuel Bertrand, Philippe Castany, Thierry Gloriant

\section{To cite this version:}

Emmanuel Bertrand, Philippe Castany, Thierry Gloriant. Investigation of the martensitic transformation and the damping behavior of a superelastic Ti-Ta-Nb alloy. Acta Materialia, 2013, 61 (2), pp.511-518. 10.1016/j.actamat.2012.09.065 . hal-00926947

\section{HAL Id: hal-00926947 https://hal.science/hal-00926947}

Submitted on 13 Jan 2014

HAL is a multi-disciplinary open access archive for the deposit and dissemination of scientific research documents, whether they are published or not. The documents may come from teaching and research institutions in France or abroad, or from public or private research centers.
L'archive ouverte pluridisciplinaire HAL, est destinée au dépôt et à la diffusion de documents scientifiques de niveau recherche, publiés ou non, émanant des établissements d'enseignement et de recherche français ou étrangers, des laboratoires publics ou privés. 


\title{
Investigation of the martensitic transformation and the damping behavior of a superelastic Ti-Ta-Nb alloy
}

\author{
E. Bertrand, P. Castany, T. Gloriant \\ UMR CNRS 6226 Institut des Sciences Chimiques de Rennes, INSA Rennes, 20 \\ Avenue des Buttes de Coësmes, 35708 Rennes Cedex 7, France
}

\begin{abstract}
In this study the $\alpha^{\prime \prime}$ stress-induced martensitic transformation and damping behaviour of the superelastic $\beta-\mathrm{Ti}-25 \mathrm{Ta}-25 \mathrm{Nb}$ alloy are investigated by tensile tests at room temperature and by dynamic mechanical analysis (DMA) in tensile mode for different applied stresses. Tensile tests show a fully non-linear elastic domain and, consequently, a specific method is proposed to determine the elastic modulus. Due to the wide range of temperature over which the martensitic transformation occurs in this class of alloys, the martensitic start temperature, $M_{\mathrm{s}}$, is not a relevant parameter to characterize the transformation and the temperature $M_{\max }$ corresponding to the temperature of maximum transformation is used. The important gap between these two temperatures explains the fully non-linear elastic behaviour of this alloy during conventional tensile tests. It is observed that two main damping sources occur in this alloy: friction at austenite/martensite interfaces during the martensitic transformation and friction at martensite/martensite interfaces at lower temperature. However, a third unexpected damping peak is also observed at high stress. Its origin is discussed with respect to the orientation of the applied stress and with regard to the most favourably oriented martensite variants determined by Schmid factor analysis.
\end{abstract}

Keywords: Titanium alloys; Shape memory alloys; Dynamic mechanical analysis; Martensitic transformation; Damping 


\section{Introduction}

Shape memory and superelastic alloys possess peculiar mechanical properties, such as a large recoverable strain, due to thermo-elastic martensitic transformation from the austenite phase to the martensitic phase. Martensitic transformations are usually described using characteristic temperatures, such as the martensite start, martensite finish, austenite start and austenite finish temperatures, respectively denoted $M_{\mathrm{s}}, M_{\mathrm{f}}, A_{\mathrm{s}}$ and $A_{\mathrm{f}}$ [1] and [2]. These temperatures can be measured by dynamic mechanical analysis (DMA): the martensitic transformation is thus generally characterized by a drop in the dynamic elastic modulus associated with an increase in the damping factor tan $\delta$ [3], [4] and [5].

The damping capacity (equivalent to internal friction) of a material is defined as its capacity to convert its mechanical energy (or vibration) into heat [6]. As damping is a typical property of shape memory and superelastic alloys these alloys are of special interest as high damping materials for specific applications, including noise and vibration reduction [7], [8] and [9]. In such alloys the reversible movement of austenite/martensite boundaries induces mechanical energy dissipation and constitutes a damping source when the initial microstructure is composed of austenite. This damping capacity is due to hysteresis of the martensitic transformation [4] and [10]. When the microstructure of shape memory alloys (SMAs) is composed of martensite another damping source is the reversible re-orientation of martensite variants of the self-accommodating microstructure, due to the hysteretic movement of twin boundaries between martensite variants [4] and [10]. These two phenomena are commonly detected by DMA as an increase in the damping factor: at low temperature when the microstructure is essentially composed of martensite for the re-orientation peak and at high temperature for the martensitic transformation peak. The internal friction in SMA such as $\mathrm{Ni}-$ Ti-based or $\mathrm{Cu}-\mathrm{Zn}$-based alloys has been widely characterized using torsion pendulum or dynamic mechanical analysers (working in free and forced vibration mode, respectively) [5], [10] and [11]. In SMA and metallic materials another well-known damping source, the Snoek effect, is a relaxation process due to the stress-induced reversible movement of solute interstitial elements such as carbon, oxygen, nitrogen or hydrogen [3], [6], [12], [13] and [14]. Metastable $\beta$-titanium alloys are known to show a stress-induced martensitic transformation from the $\beta$ phase (bcc) to $\alpha^{\prime \prime}$ phase (C-orthorhombic) [15] and [16]. Recently Ni-free SMA for biomedical applications have been a subject of interest due to the possibility of producing them from only biocompatible elements, such as tantalum, niobium and zirconium [17], [18] and [19]. In contrast to most SMA, metastable titanium alloys have a non-ordered 
austenitic structure and exhibit excellent cold workability [19], [20] and [21]. Very few DMA studies of the stress-induced martensitic (SIM) transformation and damping behaviour of these alloys have been conducted. In the literature only one study concerns characterization of the damping capacity due to the SIM transformation [22], although Snoek relaxation damping due to a high oxygen content has been reported [6], [23] and [24].

The objective of this study is to characterize the $\alpha^{\prime \prime}$ stress-induced martensitic transformation and damping behaviour of the metastable alloy $\beta-\mathrm{Ti}-25 \mathrm{Ta}-25 \mathrm{Nb}$ (mass $\%$ ) by tensile tests at room temperature and by DMA in tensile mode for different applied stresses.

\section{Materials and methods}

The Ti-25Ta-25Nb (mass\%) alloy was elaborated by cold crucible levitation melting (CCLM) to ensure melting of the high content of tantalum, which has a much higher melting point than titanium. The elements used were commercially pure titanium and pure tantalum and niobium (99.9\% purity). The ingots obtained then underwent a thermo-mechanical protocol composed of a solution treatment at $950{ }^{\circ} \mathrm{C}$ for $20 \mathrm{~h}$, cold rolling $(\mathrm{CR}=98 \%)$ and, finally, a recrystallization treatment at $850{ }^{\circ} \mathrm{C}$ for $0.5 \mathrm{~h}$, before being quenched in water.

As it is important to characterize the recrystallized microstructure, texture measurements were carried out in a Philips PW1830 X-ray generator, using $\mathrm{Cu} K_{\alpha 1}$ radiation $(\lambda=0.15406 \mathrm{~nm})$, equipped with a PW3020 texture goniometer. The orientation distribution function (ODF) was then calculated by the harmonic method. An Instron 3369 tensile test rig was used with normalized flat specimens strained along the rolling direction. Tensile tests were carried out at room temperature $\left(\sim 20^{\circ} \mathrm{C}\right)$ at a strain rate of $10^{-4} \mathrm{~s}^{-1}$. DMA was carried out with a Metravib DMA50 in tensile mode. Samples for DMA were cut with a low speed diamond wire saw. Thermal cycling was between $-130{ }^{\circ} \mathrm{C}$ and $80^{\circ} \mathrm{C}$ at a rate of $2{ }^{\circ} \mathrm{C} \min ^{-1}$. Higher temperatures were avoided in order to prevent the formation of isothermal wphase [25], [26] and [27]. The frequency of dynamic mechanical loading was $1 \mathrm{~Hz}$, and the dynamic/static ratio was kept at $\sigma_{\text {dyn }} / \sigma_{\text {stat }}=1 / 4$. The tests were performed with the tensile direction parallel to the rolling direction at maximum stress values of 50,100,150, 200 and $250 \mathrm{MPa}$, the maximum stress being defined as $\sigma_{\max }=\sigma_{\text {dyn }}+\sigma_{\text {stat }}$. Determination of the characteristic martensitic temperatures was based on the intersection of tangents. 


\section{Results and discussion}

\subsection{Texture evaluation}

The recrystallized microstructure of the Ti-25Ta- $25 \mathrm{Nb}$ alloy was analysed by optical microscopy and X-ray diffraction in a previous work and is composed only of equiaxed $\beta$ grains of a few tens of microns [17]. In the present study the crystallographic texture was particularly evaluated by X-ray diffraction of the $\{110\},\{200\}$ and $\{211\}$ crystallographic planes of the $\beta$ phase. Fig. 1 shows the corresponding calculated pole figures obtained. The main crystallographic orientation along the rolling direction was $\left\langle\begin{array}{lll}1 & 10\end{array}\right.$, which corresponds to the $\{\mathrm{hkl}\}\left\langle\begin{array}{lllll}1 & 1 & 0\end{array} \quad \alpha\right.$ fiber in bcc metals [28] and [29]. The inverse pole figure (IPF) along the rolling direction highlights the prevalence of this fiber (Fig. 2). As tensile tests and DMA measurements were carried out along the rolling direction it is likely that the $\left\langle\begin{array}{llll}1 & 1 & 0\end{array}\right\rangle$ direction largely lies along the tensile direction. Moreover, the amplitude of the strain due to stress-induced martensitic transformation is maximized along the $\langle 110$ > crystallographic orientation [30], which can be used to characterize the martensitic transformation in this alloy.

\subsection{Tensile tests and elastic modulus measurement}

The tensile curve obtained for the alloy Ti-25Ta-25Nb, given in Fig. 3, is typical of superelastic alloys exhibiting a two stage yielding behaviour. The first stage of yielding, also termed the stress plateau, occurs between 230 and $290 \mathrm{MPa}$ and is due to stress-induced martensitic (SIM) transformation of the $\beta$ phase to $\alpha^{\prime \prime}$ martensite, as shown during cyclical tensile tests performed in a previous work [17]. The critical stress of this first plateau, $\sigma_{c}$, i.e. the stress at which the SIM transformation starts, has a value of $230 \mathrm{MPa}$. Beyond $290 \mathrm{MPa}$ no further phase transformation occurs and the strain is accommodated first by conventional elasticity and then by plastic deformation mechanisms, such as slip or twinning, which are commonly observed in this kind of alloy [31], [32], [33] and [34]. An enlargement of the initial stage of the tensile curve (Fig. 3b) shows that the elastic domain is fully non-linear. One can suppose that this non-linearity is due to a partial martensitic transformation that might occur when the stress is below oc. This point will be discussed in Section 3.5.

Generally determination of the elastic modulus of conventional alloys consists simply of measuring the slope in the elastic domain on stress-strain curves. This determination is more difficult with superelastic or SMAs because there may be no linear elastic domain, as observed in the present study. Several techniques were applied to measure the elastic modulus 
on tensile curves with non-linear elastic domains, like the secant modulus $E_{\mathrm{s}}(\varepsilon)=\sigma / \varepsilon$ which is the average modulus between the curve origin and an arbitrary point $(\varepsilon, \sigma)[16]$ and [35]. In this paper the elastic modulus $E$ is defined as shown in Fig. 3b. This new method consists of determining a point on the curve $\left(\varepsilon_{\mathrm{E}}, \sigma_{\mathrm{E}}\right)$ by the intersection of tangents. The first tangent is taken at the origin of the tensile curve, while the second corresponds to the horizontal tangent of the stress plateau. If the stress plateau is not perfectly horizontal this tangent is taken to be the inflection point of the plateau. The intersection of these tangents is projected onto the tensile curve, giving the $\left(\varepsilon_{\mathrm{E}}, \sigma_{\mathrm{E}}\right)$ point. The elastic modulus is then the secant modulus for $\varepsilon_{\mathrm{E}}$, i.e. $E=\sigma_{\mathrm{E}} / \varepsilon_{\mathrm{E}}$. This method gives the average modulus in the first elastic domain, which was $56 \mathrm{GPa}$ for the alloy investigated. In comparison with the secant modulus method, the advantage of this method is that the point used to measure the average modulus is not arbitrary.

\subsection{Determination of the characteristic temperatures of the SIM transformation by DMA}

DMA was then used to characterize the martensitic transformation that occurs during the first non-linear elastic domain before reaching the first yield point observed by tensile tests at room temperature. Determination of the characteristic temperatures is described with the measurements carried out at $\sigma_{\max }=100 \mathrm{MPa}$. Evolution of the modulus and the damping factor (tan $\delta)$ as a function of temperature during cooling and heating are presented in Fig. 4. The transformation temperatures $\left(M_{\mathrm{s}}, M_{\mathrm{f}}, A_{\mathrm{s}}, A_{\mathrm{f}}\right)$ at a given stress were determined using the modulus curves because this parameter is only sensitive to the stress-induced martensitic transformation and not to other phenomena, such as martensite re-orientation [22]. In contrast, the damping factor is sensitive to various phenomena leading to possible uncertainties in the measurement of characteristic temperatures, such as martensite re-orientation [5] and [22]. When the temperature decreases, as shown in Fig. 4a, one can observe a change in the slope of the modulus. The corresponding temperature was measured from the intersection of the two tangents of the curve (Fig. 4a). This temperature is termed the martensite start $\left(M_{\mathrm{s}}\right)$ and corresponds to the beginning of martensitic transformation. The damping factor also starts to increase when $M_{\mathrm{s}}$ is reached.

A strong reduction in the modulus associated with an increase in $\tan \delta$ was observed on cooling. The increase in tand is due to movement of the austenite/martensite interfaces during the stress-induced martensitic transformation. The minimum modulus corresponds to maximum transformation, with the corresponding temperature being denoted $M_{\max }$. This 
temperature is not a characteristic temperature currently used to characterize the SIM transformation, but as will be discussed below, $M_{\max }$ is a pertinent parameter to characterize martensitic transformation in metastable $\beta$-titanium alloys. At the stress $\sigma_{\max }$ used in this example $(100 \mathrm{MPa})$ there is good correspondence between the minimum modulus and maximum tan $\delta$.

Further, on cooling the modulus increases above that at the $M_{\max }$ temperature. The damping factor decreases, but remains higher than that at $M_{\mathrm{s}}$. In this temperature range damping is due to reversible movement of the martensite/martensite interfaces [4], [10] and [22]. This observation indicates that this alloy is probably a low temperature shape memory alloy. It should be noted that no modulus or damping factor curve characteristics enabled precise definition of the martensitic finish temperature.

Similarly, the temperatures corresponding to maximum transformation $A_{\max }$ and to the end of martensite/austenite transformation $A_{\mathrm{f}}$ (Austenite finish) were defined and measured during heating (Fig. 4b). It is noticeable that $M_{\max }$ is lower than $A_{\max }$, which is in accordance with the general properties of martensitic transformation and Le Chatellier's principle.

\subsection{Stress dependence of the characteristic temperatures}

Using the method described in the previous section these transformation temperatures were determined at various stresses. The different curves are presented in Fig. 5. The $M_{\mathrm{s}}$ and $A_{\mathrm{f}}$ temperatures cannot always be determined when the slope variation is not visible or when the temperature is outside the temperature range. With the lowest stress $\sigma_{\max }=50 \mathrm{MPa}$ a small amount of stress-induced martensite formed under dynamic stress, leading to small variations in the modulus and damping factor. Consequently, the precision of the temperature measurements was quite low at $\sigma_{\max }=50 \mathrm{MPa}$. With the highest stress $\sigma_{\max }=250 \mathrm{MPa}$ martensitic transformation can still be detected from the modulus variation, while the damping factor peak disappears. Indeed, martensite deformed plastically when it formed during cooling and, reciprocally, martensite was plastically deformed when it disappeared during heating. This plastic deformation (for example dislocations) can thus impede the movement of martensite/austenite interfaces, leading to the observed loss of damping capacity in comparison with lower stresses.

It is also worth noting that the peak damping factor at higher temperatures has a maximum value of 0.2 at $100 \mathrm{MPa}$ and decreases at higher stresses. The amplitude of the second damping factor peak (at lower temperatures) increases up to a value of 0.1 at 150-200 $\mathrm{MPa}$, and then decreases. The origin of these damping peaks will be discussed in Section 3.5. 
Evolution of the temperatures $M_{\mathrm{s}}, M_{\max }, A_{\mathrm{f}}$ and $A_{\max }$ are depicted in Fig. 6 as a function of the static stress $\sigma_{\text {stat }}\left(=0.8 \times \sigma_{\max }\right)$, which corresponds to the mean stress during the tests. Probably due to the low precision of the measurements (see above) the temperatures measured at $\sigma_{\max }=50 \mathrm{MPa}$ deviate in comparison with those at other stress values and are not taken into account in the extrapolation. The temperatures $M_{\max }, A_{\mathrm{f}}$ and $A_{\max }$ show similar behaviours, with a coefficient of $0.30 \mathrm{~K} \mathrm{MPa}^{-1}$ for each. This value is similar to that found by Buesconsejo et al. for Ti-Ta alloys [36]. However, the evolution of $M_{\mathrm{s}}$ is peculiar, with a lower dependence on stress than the other characteristic temperatures. Such a difference between $M_{\mathrm{s}}$ and the other characteristic temperatures has not been reported previously.

The temperature difference between $A_{\mathrm{f}}$ and $A_{\max }$ is constant at about $60^{\circ} \mathrm{C}$, while the difference between $M_{\mathrm{s}}$ and $M_{\max }$ decreases from $80{ }^{\circ} \mathrm{C}$ to $50{ }^{\circ} \mathrm{C}$ when the stress is increased. These differences are very important and reflect the fact that the SIM transformation occurs over a wide range of temperatures in metastable $\beta$-titanium alloys. Considering cooling, the amount of transformed phase is, however, below the $M_{\mathrm{s}}$. As a consequence, the $M_{\mathrm{s}}$ temperature determines the initial stage of transformation but is not representative of a significant volume fraction of transformed austenite. This is why we propose using $M_{\max }$ as a more representative characteristic temperature of the SIM transformation in this kind of alloy. These differences in temperature are specific to these alloys: in other SMAs, such as Ni-Tibased alloys, such differences do not exist and the temperatures $M_{\mathrm{s}}$ and $M_{\max }$ are almost the same [13]. It is also noticeable that use of the dynamic modulus curve to determine the temperature allows measurement of the actual $M_{\mathrm{s}}\left(\right.$ and $A_{\mathrm{f}}$ ) values, in contrast to other methods based on static displacement, which underestimate these differences [22] and [36]. However, the actual values of $M_{\mathrm{s}}$ and $A_{\mathrm{f}}$ do not need to be precisely known for Ni-Ti alloys, as SIM transformation occurs over a shorter temperature range, which is not the case for metastable $\beta$-titanium alloys. As an example, $M_{\mathrm{s}}$ extrapolated at zero stress in Fig. $6 \mathrm{a}$ is about $30{ }^{\circ} \mathrm{C}$, which is higher than room temperature and thus not logical for a superelastic alloy. In contrast, $M_{\max }$ extrapolated at zero stress was found to be about $-60^{\circ} \mathrm{C}$, which is logical for a superelastic alloy. Consequently, $M_{\max }$ is clearly better than $M_{\mathrm{s}}$ in characterizing the superelastic and shape memory behaviour of metastable $\beta$-titanium alloys.

\subsection{Comparison between DMA measurements and tensile tests}

In order to correlate the stress-strain tensile curves (at $\mathrm{T}=20^{\circ} \mathrm{C}$ ) and the DMA measurements the stresses $\sigma_{M s, 20^{\circ} \mathrm{C}}$ and $\sigma_{M \max , 20^{\circ} \mathrm{C}}$ are needed. These stresses correspond to the values of $M_{\mathrm{s}}$ and $M_{\max }$ at $20^{\circ} \mathrm{C}$. By extrapolation of the curves in Fig. 6a $\sigma_{M \max , 20^{\circ} \mathrm{C}}$ is 
determined to be $260 \mathrm{MPa}$, while $\sigma_{M s, 20^{\circ} \mathrm{C}}$ is negative, which means that a small amount of austenite had already begun to transform to martensite at room temperature when no stress was applied. The $\sigma_{M \max , 20^{\circ} \mathrm{C}}$ value is reported on the stress-stress curves in Fig. 7. As the first stage of the tensile curve lies between $\sigma_{M s, 20^{\circ} \mathrm{C}}$ and $\sigma_{M \max , 20^{\circ} \mathrm{C}}$ it is clear that a small amount of stress-induced martensitic transformation occurred immediately when stress was applied at room temperature. SIM transformation increased progressively as the stress was increased. Consequently, the full non-linearity of the elastic domain of the tensile curve shown in Fig. 2 is due to this low level of SIM transformation, which lowers the tangent modulus. This nonlinearity has been observed in various metastable $\beta$-titanium alloys, but was ignored or not explained [35], [37] and [38]. Finally, maximum transformation occurred when the stress $\sigma_{M \max , 20^{\circ} \mathrm{C}}$ was reached, i.e. $260 \mathrm{MPa}$, which is in perfect accordance with the stress plateau of the tensile curve (Fig. 7).

In summary, the non-linear elastic behaviour observed in tensile curves occurs when the stress is between $\sigma_{M s, 20^{\circ} \mathrm{C}}$ and $\sigma_{M \max , 20^{\circ} \mathrm{C}}$, while the first yielding due to SIM transformation occurs when the stress is around $\sigma_{M \max , 20{ }^{\circ} \mathrm{C}}$.

\subsection{Damping sources}

Two damping sources are known to occur in superelastic and SMAs. The highest temperature damping source observed in this study was accompanied by a reduction in the modulus occurring during the $\beta-\alpha^{\prime \prime}$ stress-induced martensitic transformation, leading to a well-defined peak in tand. This peak is due to the high mobility of the austenite/martensite interfaces. In the martensite phase the low temperature damping source is not accompanied by a reduction in the modulus, leading to a broad peak in tand. This peak is due to reversible movement of the martensite/martensite twin interfaces. These two peaks in tan $\delta$ are clearly visible in Fig. 5 for each value of applied stress.

However, a careful analysis of the evolution of tan $\delta$ at high stress suggests the existence of a third peak between the two well-known peaks. In particular, this assumption is supported by the fact that the first peak in tan $\delta$ is not related to the modulus minimum at stresses higher than $\sigma_{\max }=100 \mathrm{MPa}$. As an example, Fig. 8 shows DMA curves during cooling at $\sigma_{\max }=200 \mathrm{MPa}$. This figure clearly shows that the tan $\delta$ maximum does not correspond to the modulus minimum.

Hence, the tand curve was deconvoluted in order to determine the number of damping sources. As no modelling of the damping peak due to stress-induced martensitic transformation is available, Gaussian curves were used as a first approximation. In Fig. 8 the 
Gaussian curve number 1 corresponds to the martensitic transformation and is thus centered at $M_{\max }$, i.e. this damping peak has to coincide with the modulus minimum. The Gaussian curve number 2 corresponds to martensite re-orientation at low temperature, but a third Gaussian curve, number 3 , is necessary to obtain accurate deconvolution with correspondence between $M_{\max }$ and the maximum of the Gaussian curve number 1 . This third peak is located below $M_{\max }$ and only occurs when high stress is applied. This phenomenon has not been observed in previous studies [22], since the applied stress was lower than the stresses used in the present study.

Two other sources of damping are commonly observed in SMAs, and could be the source of this third peak. The first concerns the stress-induced re-orientation of interstitial atoms, termed Snoek-type relaxation. However, this damping source cannot explain this third peak, because the characteristic temperatures of this phenomenon are not in the temperature range observed: above $200{ }^{\circ} \mathrm{C}$ for oxygen or nitrogen [6], [14] and [24] and less than $-100{ }^{\circ} \mathrm{C}$ for hydrogen [6] and [14]. Moreover, these elements may only exist as impurities in this alloy and their content is not high enough to give such a magnitude of damping. The second concerns the reversible movement of dislocation. As this phenomenon is only observable at high frequency $(\mathrm{MHz})$ [14], [39] and [40] it cannot explain the presence of the third peak, since the frequency used for the tests was $1 \mathrm{~Hz}$.

Our suggestion is that this third peak is due to friction between two different variants of stress-induced martensite. Indeed, due to the strong texture of the $\beta$ phase of the samples tested one can first assume these are single crystals $\left\langle\begin{array}{llll}1 & 1 & 0\end{array}\right\rangle$ directed along the tensile direction. However, in spite of this strong texture, there is some deviation from this ideal orientation (Fig. 2) that can lead to grains with different behaviours. In order to analyse this we used an analysis based on Schmid factors to determine the number of variants that are activated depending on the specific crystallographic orientation of the grains.

\subsection{Schmid factor analysis of the SIM transformation}

As SIM transformation can be described as the slip of partial dislocations leading to a stacking fault corresponding to the martensite phase, the method described in a previous paper to calculate the Schmid factor for twinning in the $\beta$ phase can be used [33]. Moreover, the normal component of transformation deformation is negligible compared with the shear component in most thermo-elastic martensitic transformations and the Schmid factor can be used [41]. In the case of martensitic transformations the slip plane and the shear direction 
used for twinning are replaced by the habit plane and the invariant strain direction, respectively. According to the literature [42] and [43] habit planes can be taken as $\{755\}_{\beta}$ and invariant strain directions as $\langle 7710\rangle_{\beta}$. Consequently, the Schmid factor can be calculated by considering the geometry of the $\langle 7710\rangle_{\beta}\{755\}_{\beta}$ system. To be activated during tensile tests a variant has to have a higher Schmid factor than other samples, i.e. this variant has to be geometrically preferentially oriented.

If the tensile direction lies exactly along the $\left\langle\begin{array}{llll}1 & 1 & 0\end{array}\right\rangle_{\beta}$ direction, which is true of the majority of grains considering the texture (Fig. 2), two habit plane variants always have the highest Schmid factor value, equal to 0.50. These two variants correspond to the same lattice correspondence variant $(\mathrm{CV})$, i.e. both variants give the same crystallographic orientation of the martensite. No other variant can be activated for this loading direction. For this specific orientation Inamura et al. [22] calculated that a unique CV of the martensite $\alpha^{\prime \prime}$ is preferentially oriented to interact with the applied stress. This approach allows prediction of which CV is preferentially activated during a tensile test (or DMA in tensile mode) by considering the $\mathrm{CV}$ that gives the maximum strain during deformation. In comparison with a Schmid factor analysis, both methods give the same result and are almost equivalent: one method gives the preferentially oriented CV while the other one gives the two habit plane variants corresponding to the same $\mathrm{CV}$.

However, even if the texture is strong there is some deviation from the ideal configuration, with $\left\langle\begin{array}{llll}1 & 1 & 0\end{array}\right\rangle_{\beta}$ along the tensile direction (Fig. 2). For example, a deviation of less than $20^{\circ}$ from this ideal configuration can lead to possible activation of variants of the two different $\mathrm{CV}$. Possible tensile directions corresponding to this configuration are, for example, $\langle 531$ \rangle$_{\beta},\langle 741\rangle_{\beta}$ and $\langle 210\rangle_{\beta}$ : in these cases the highest Schmid factor values of the preferential CV were 0.45 , while another CV has a Schmid factor value of 0.12 . The second $\mathrm{CV}$ had a low Schmid factor value but, when the stress was high enough the resolved critical stress was most probably high enough to allow activation of this second $\mathrm{CV}$. The friction of interfaces between these two different $\mathrm{CV}$ is thus a possible explanation of the third observed damping peak. This assumption is supported by the fact that this third peak was only observed at high applied stresses for the present $\mathrm{Ti}-25 \mathrm{Ta}-25 \mathrm{Nb}$ alloy $\left(\sigma_{\max } \geqslant 150 \mathrm{MPa}\right)$. It should be mentioned that friction of interfaces between two different $\mathrm{CV}$ is only possible in the temperature domain corresponding to existence of the $\beta$ phase, in which two $\mathrm{CV}$ can be activated, and before the volume fraction of martensite becomes too great. This assumption is 
consistent with the fact that this third damping peak is experimentally observed between the other two in this study.

In summary, with a strong $\{\mathrm{hkl}\}\left\langle\begin{array}{lll}1 & 1 & 0\end{array}\right\rangle$ texture that leads to the highest superelastic strain the first damping peak (peak 1 in Fig. 8) is due to interfacial friction between the austenite and one unique $\mathrm{CV}$ of the martensite, depending on the orientation of each grain. At relatively high stresses, as the temperature decreases, a second $\mathrm{CV}$ of martensite can be formed in grains in which a first CV was previously activated. The additional friction between these two $\mathrm{CV}$ leads to an additional damping peak (peak 3 in Fig. 8). When the temperature is again decreased the microstructure becomes fully martensitic and the well-known broad damping peak observed (peak 2 in Fig. 8), due to friction between the martensite/martensite twin interfaces during the re-orientation process.

\section{Conclusion}

Martensitic transformation of the superelastic alloy $\beta$-Ti-25Ta-25Nb was investigated by tensile testing and by DMA in tensile mode. The thermo-mechanical treatment used produced a strong texture with the $\left\langle\begin{array}{llll}1 & 1 & 0\end{array}\right\rangle_{\beta}$ direction along the tensile direction, which is suitable for an analysis of superelasticity.

The characteristic temperatures of martensitic transformation were measured from the modulus curves obtained by DMA for different applied stresses. Martensitic transformation was shown to occur over a wide range of temperatures, leading to the proposition of the novel characteristic temperatures $M_{\max }$ and $A_{\max }$, corresponding to maximum transformation. These two temperatures allow a more accurate characterization of martensitic transformation in metastable $\beta$-titanium alloys. The important difference between $M_{\max }$ and $M_{\mathrm{s}}$ explains the nonlinear elastic behaviour observed in tensile curve: this is due to partial martensitic transformation, which was shown to occur below the stress plateau if the tensile curve.

SIM transformation and martensite re-orientation are highlighted by two distinct damping peaks during DMA. An increase in the applied stress leads to a shift in the tan $\delta$ maximum compared with the modulus minimum resulting from the existence of a third damping source when the applied stress ws high enough $\left(\sigma_{\max } \geqslant 150 \mathrm{MPa}\right)$. This third damping peak was attributed to friction between the interfaces of two lattice CVs that are not formed at the same temperature due to deviations in the ideal grain orientation. This hypothesis was supported by a Schmid factor analysis of the stress-induced martensitic transformation. In addition, this 
approach was proved to be a pertinent method to predict the martensite variants activated during uniaxial tensile deformation.

\section{Acknowledgement}

This research was funded within the framework of the Eurêka/MNT ERA-Net European

Consortium Project "NanoBioAll" (E!4482): Advanced Metallic Biomaterials, NanoStructured, for Implantable Medical Devices.

\section{References}

[1] Lovey FC, Torra V. Prog Mater Sci 1999;44:189.

[2] Otsuka K, Ren X. Prog Mater Sci 2005;50:511.

[3] Nowick AS. Prog Metal Phys 1953;4:1.

[4] Liu Y, Van Humbeeck J, Stalmans R, Delaey L. J Alloys Compd 1997;247:115.

[5] Mercier O, Melton KN, De Préville Y. Acta Metall 1979;27:1467.

[6] Yin F, Iwasaki S, Ping D, Nagai K. Adv Mater 2006;18:1541.

[7] Van Humbeeck J. Mater Sci Eng A 1999;273:134.

[8] Van Humbeeck J, Kustov S. Smart Mater Struct 2005;14:S171.

[9] Van Humbeeck J, Liu Y. Mater Sci Forum 2000;327-3:331.

[10] Van Humbeeck J. J Alloys Compd 2003;355:58.

[11] Ghilarducci A, Ahlers M. Scripta Metall 1980;14:1341.

[12] Teus SM, Shyvanyuk VN, Gavriljuk VG. Acta Mater 2006;54:3773.

[13] Mazzolai FM, Biscarini A, Coluzzi B, Mazzolai G, Villa E, Tuissi A. Acta Mater 2007;55:4243.

[14] Nowick AS, Berry BS. Anelastic Relaxation in Crystalline Solids. New York: Academic Press, 1972.

[15] Kim HY, Ikehara Y, Kim JI, Hosoda H, Miyazaki S. Acta Mater 2006;54:2419.

[16] Laheurte P, Prima F, Eberhardt A, Gloriant T, Wary M, Patoor E. J Mech Behav Biomed Mater 2010;3:565.

[17] Bertrand E, Gloriant T, Gordin DM, Vasilescu E, Drob P, Vasilescu C, Drob SI. Journal of the Mechanical Behavior of Biomedical Materials 2010;3:559.

[18] Eisenbarth E, Velten D, Müller M, Thull R, Breme J. Biomater 2004;25:5705. 
[19] Ramarolahy A, Castany P, Prima F, Laheurte P, Péron I, Gloriant T. J Mech Behav Biomed Mater 2012;9:83.

[20] Buenconsejo PJS, Kim HY, Miyazaki S. Scripta Mater 2011;64:1114.

[21] Besse M, Castany P, Gloriant T. Acta Mater 2011;59:5982.

[22] Inamura T, Yamamoto Y, Hosoda H, Kim HY, Miyazaki S. Acta Mater 2010;58:2535.

[23] Yin F, Yu L, Ping D. Mater Sci Eng A 2009;521-522:372.

[24] Lu H, Li CX, Yin FX, Fang QF, Umezawa O. Mater Sci Eng A 2012;541:28.

[25] Mantani Y, Tajima M. Mater Sci Eng A 2006;438-440:315.

[26] Mantani Y, Tajima M. Mater Sci Eng A 2006;442:409.

[27] Zhou YL, Niinomi M, Akahori T. Mater Sci Eng A 2004;384:92.

[28] Raabe D, Läcke K. Scripta Metall Mater 1992;27:1533.

[29] Sander B, Raabe D. Mater Sci Eng A 2008;479:236.

[30] Kim HY, Sasaki T, Okutsu K, Kim JI, Inamura T, Hosoda H, Miyazaki S. Acta Mater 2006;54:423.

[31] Oka M, Taniguchi Y. Metall Mater Trans A 1979;10:651.

[32] Castany P, Besse M, Gloriant T. Phys Rev B 2011;84:020201.

[33] Bertrand E, Castany P, Péron I, Gloriant T. Scripta Mater 2011;64:1110.

[34] Castany P, Besse M, Gloriant T. Scripta Mater 2012;66:371.

[35] Elias LM, Schneider SG, Schneider S, Silva HM, Malvisi F. Mater Sci Eng A 2006;432:108.

[36] Buenconsejo PJS, Kim HY, Hosoda H, Miyazaki S. Acta Mater 2009;57:1068.

[37] Miyazaki S, Kim HY, Hosoda H. Mater Sci Eng A 2006;438-440:18.

[38] Al-Zain Y, Kim HY, Koyano T, Hosoda H, Nam TH, Miyazaki S. Acta Mater 2011;59:1464.

[39] Pérez-Landazábal JI, Recarte V, Agosta DS, Sánchez-Alarcos V, Leisure RG. Phys Rev B 2006;73:224101.

[40] Salje EKH, Zhang H, Idrissi H, Schryvers D, Carpenter MA, Moya X, Planes A. Phys Rev B 2009;80:134114.

[41] Christian JW. Metall Trans A 1982;13:509.

[42] Chai YW, Kim HY, Hosoda H, Miyazaki S. Acta Mater 2009;57:4054.

[43] Inamura T, Kim JI, Kim HY, Hosoda H, Wakashima K, Miyazaki S. Philosophical Magazine 2007;87:3325. 
$\{110\}$

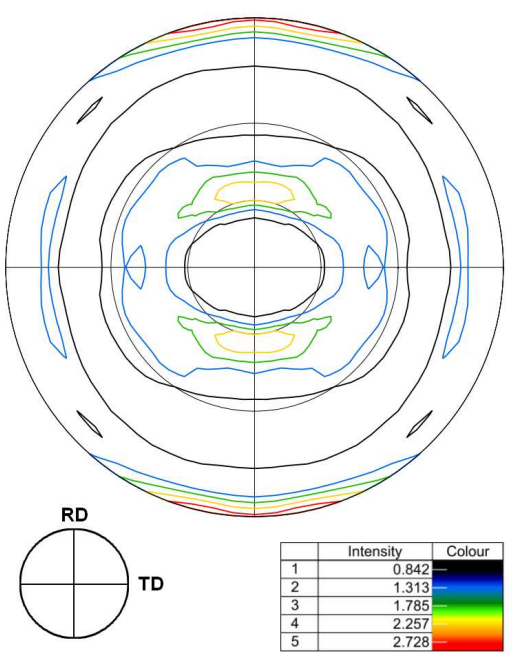

$\{200\}$

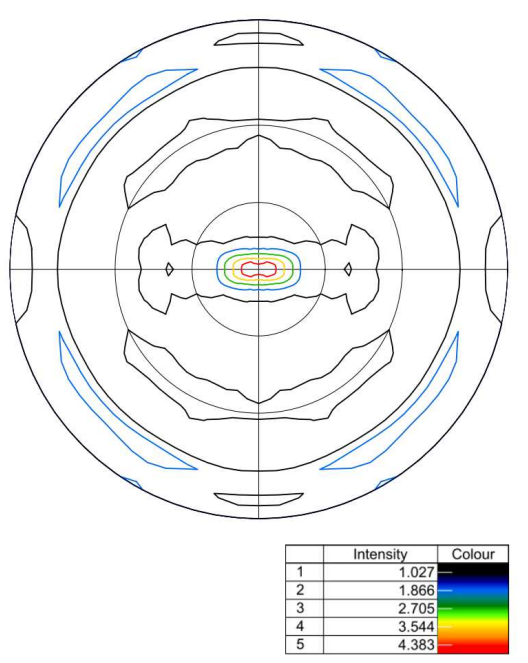

$\{211\}$

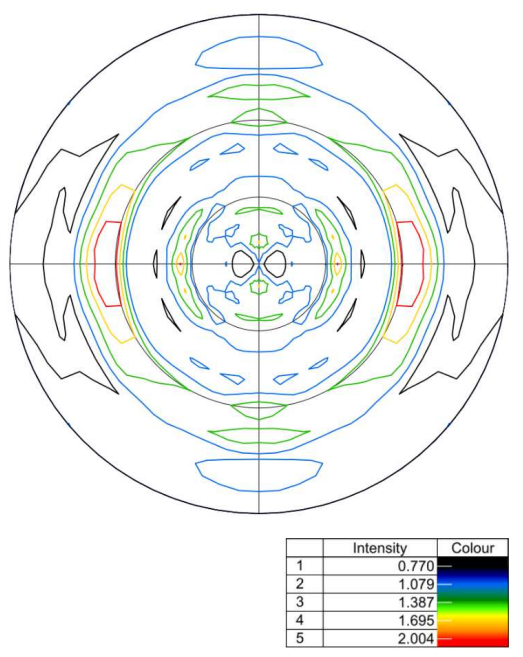

Fig. 1. Calculated pole figures highlighting the $\alpha$ fiber. RD, rolling direction; TD, transverse direction. 


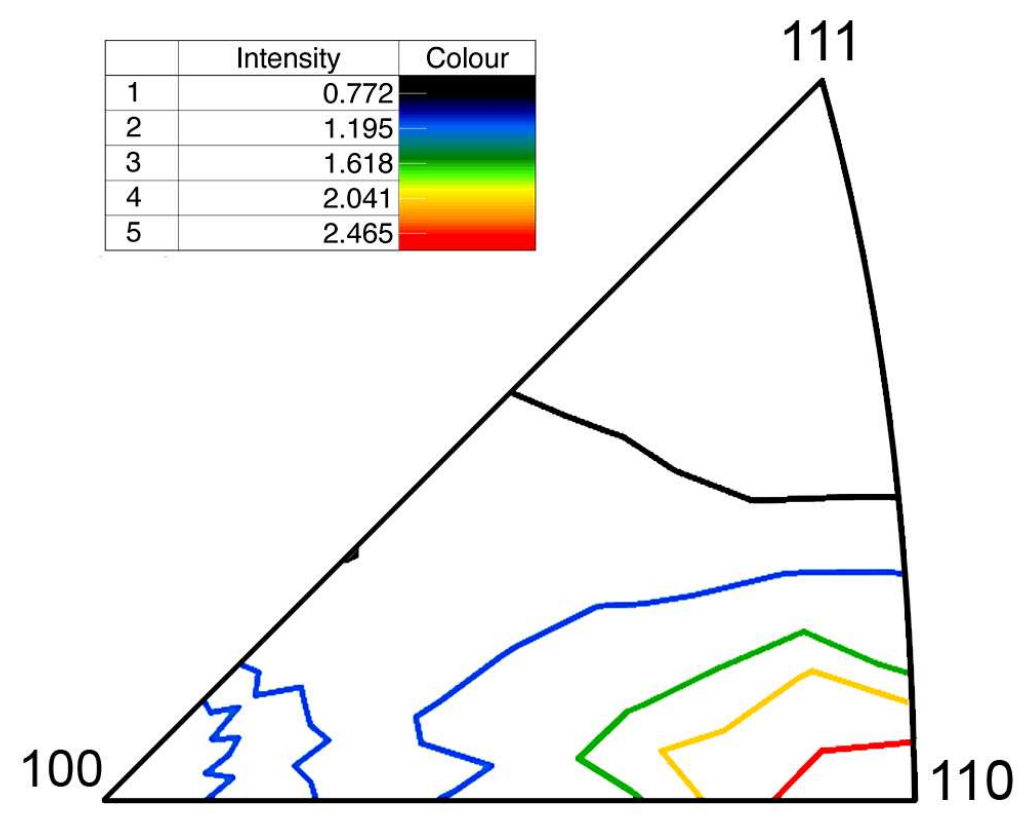

Fig. 2. Inverse pole figure along the rolling direction. 

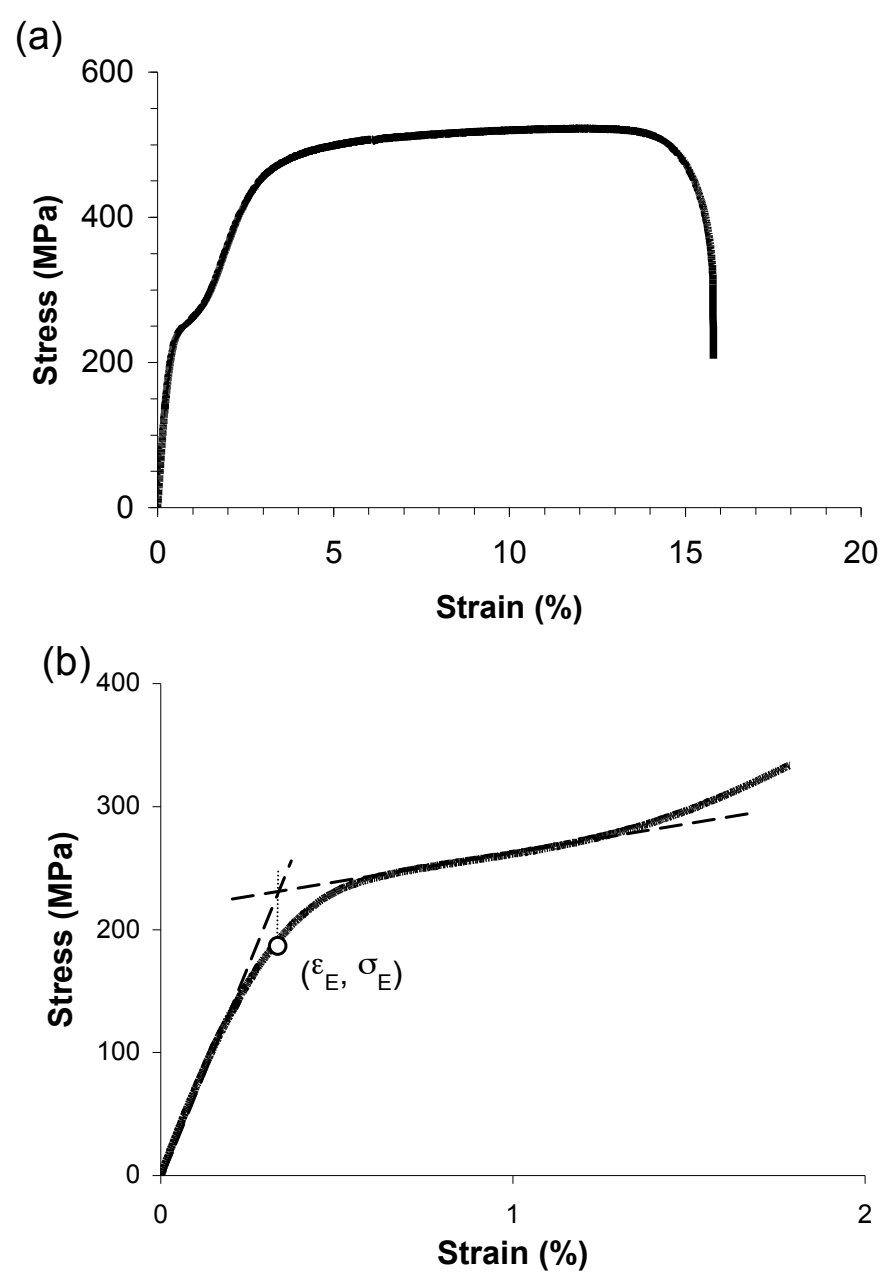

Fig. 3. (a) Tensile stress-strain curve of the Ti-25Ta-25Nb alloy and (b) a description of the method used to determine the elastic modulus. 
(a)

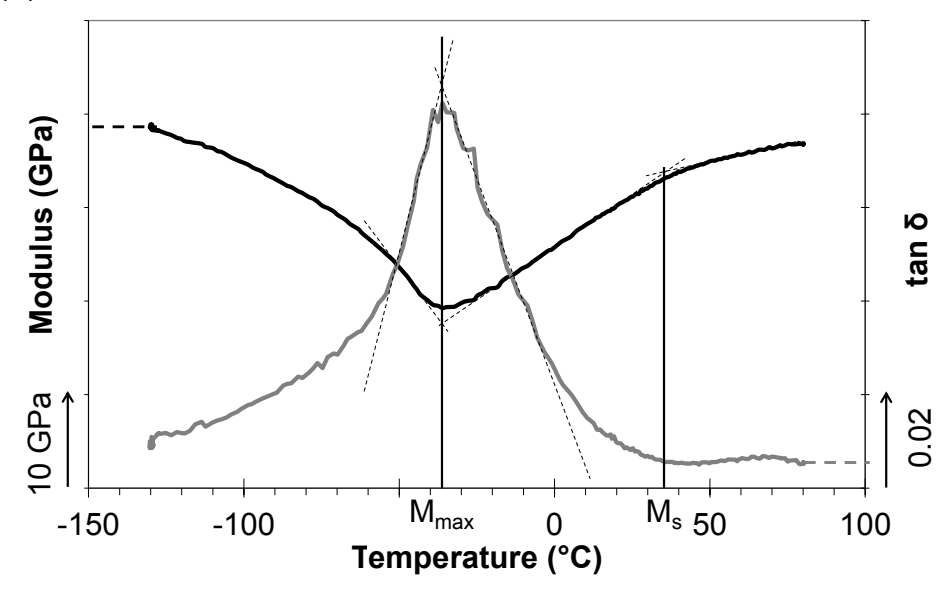

(b)

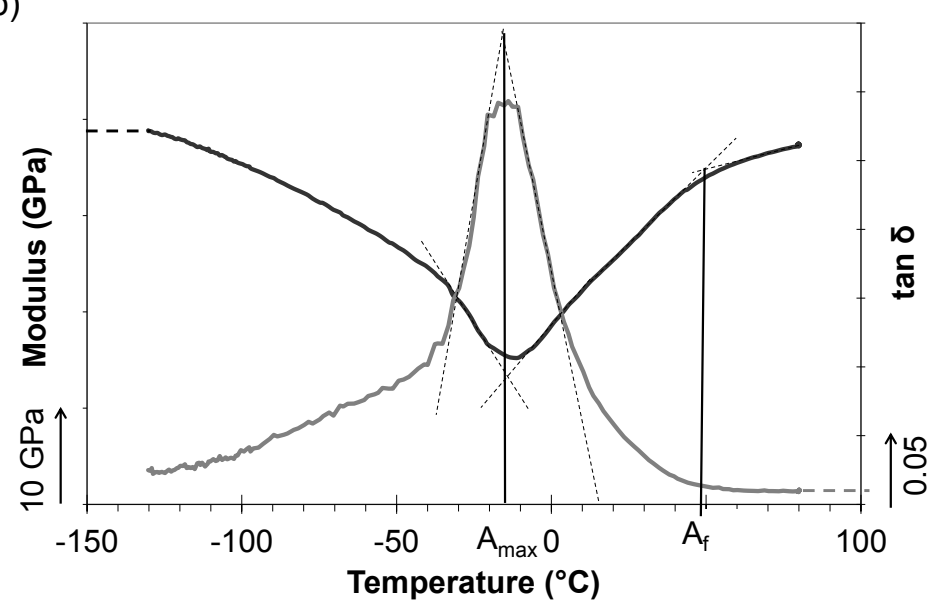

Fig. 4. Modulus and tan $\delta$ (in black and grey, respectively) as a function of temperature during (a) cooling and (b) heating for $\sigma_{\max }=100 \mathrm{MPa}$; the temperatures characterizing the SIM transformation $M_{\max } / A_{\max }$ and $M_{\mathrm{s}} / A_{\mathrm{f}}$ are indicated. 
Cooling

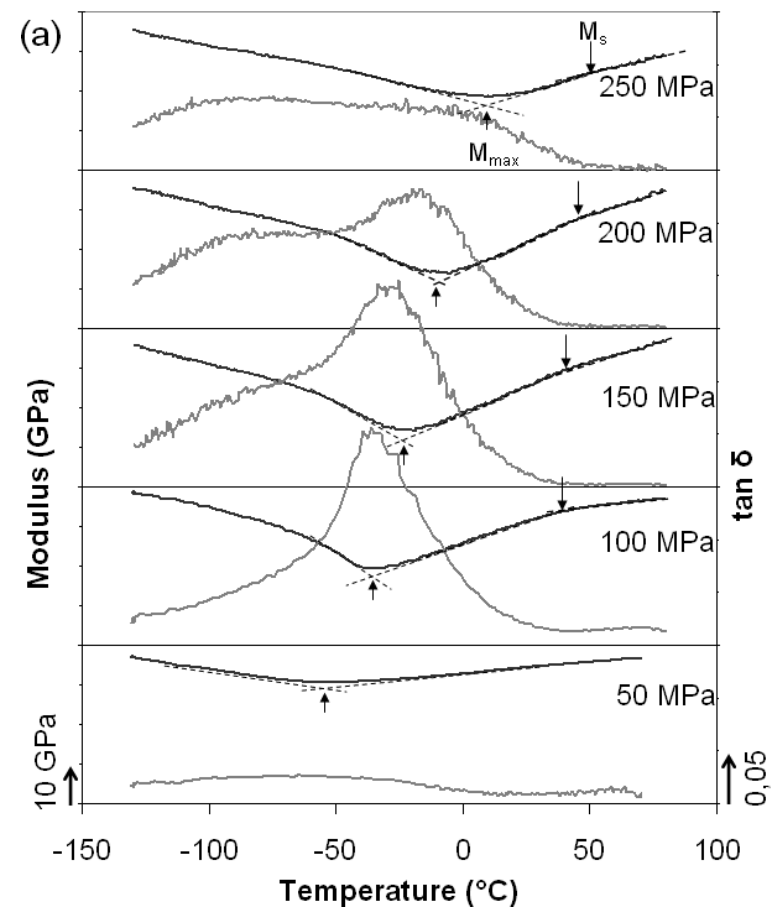

Heating

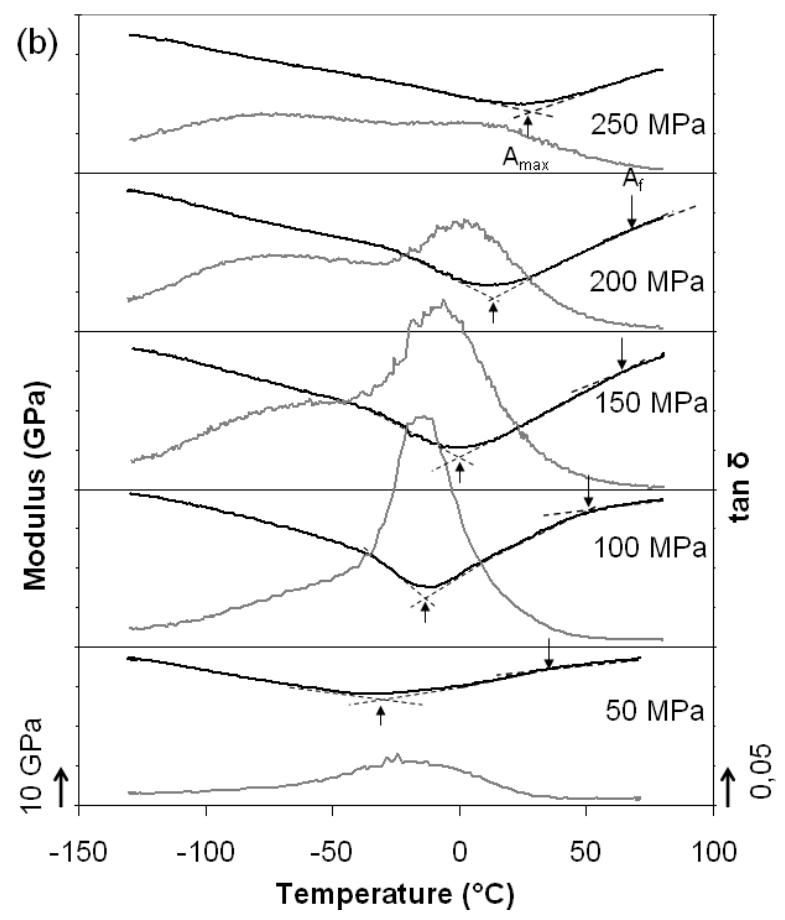

Fig. 5. Modulus and damping factor (in black and grey, respectively) as a function of the temperature at different stresses $\sigma_{\max }$ during cooling and heating. 

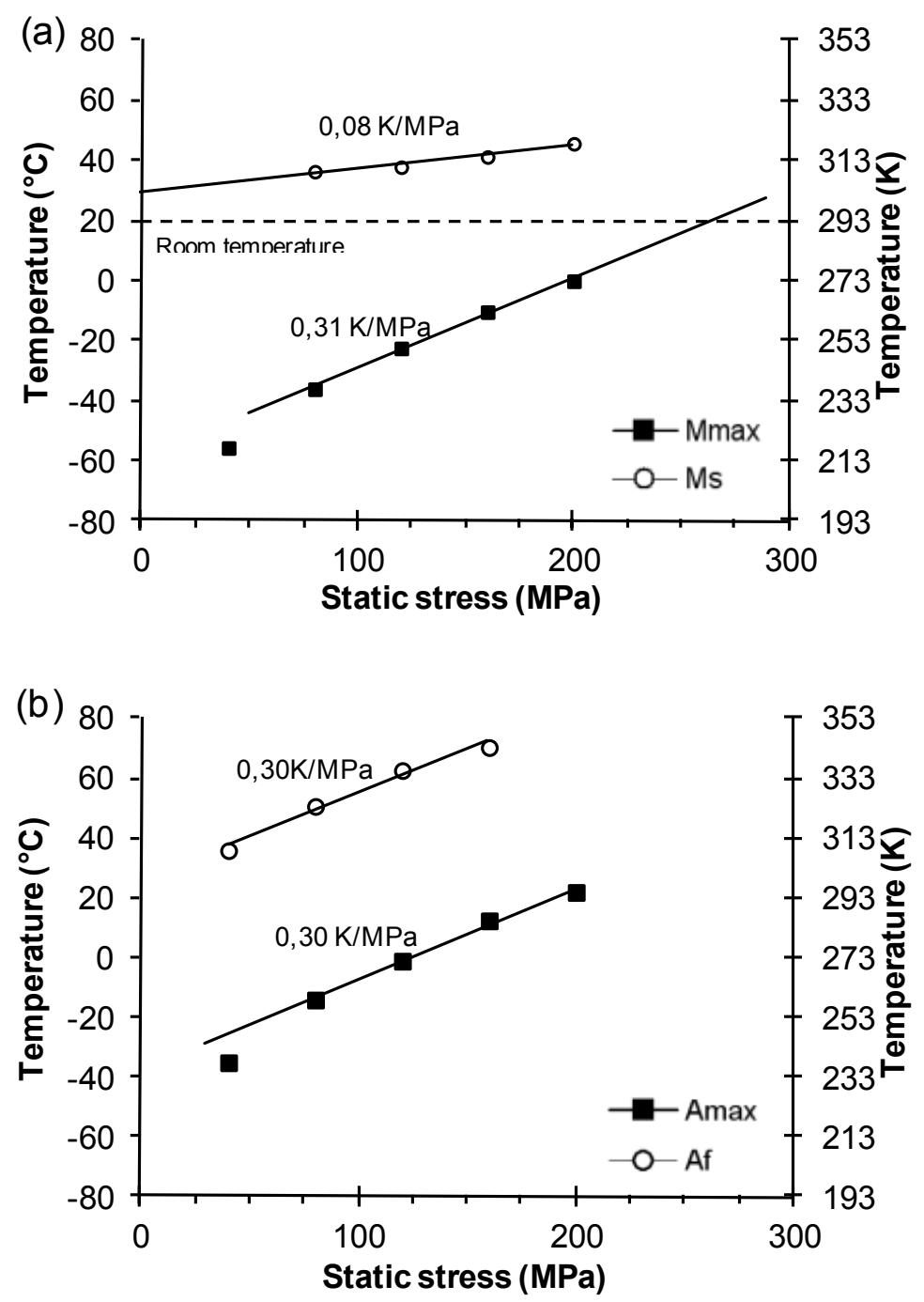

Fig. 6. Characteristic temperatures (a) $M_{\mathrm{s}}, M_{\max }$ and (b) $A_{\mathrm{f}}, A_{\max }$ as a function of the static stress. 


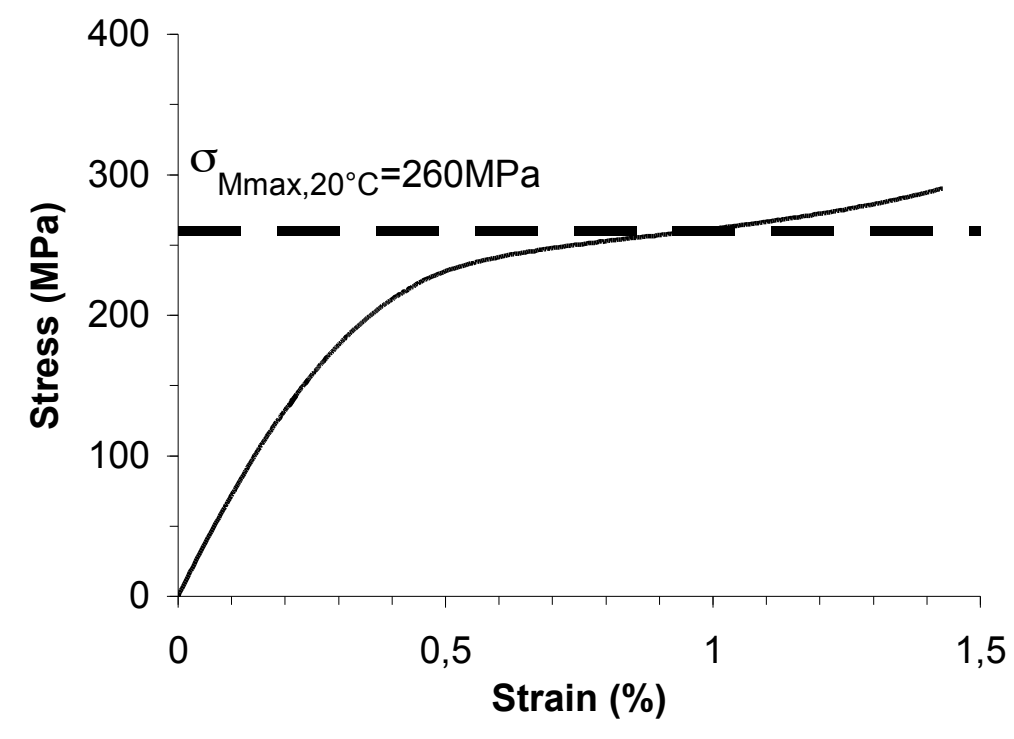

Fig. 7. First stage of the stress-strain curve in Fig. 3 for the stress value corresponding to $M_{\max }$ at room temperature. 


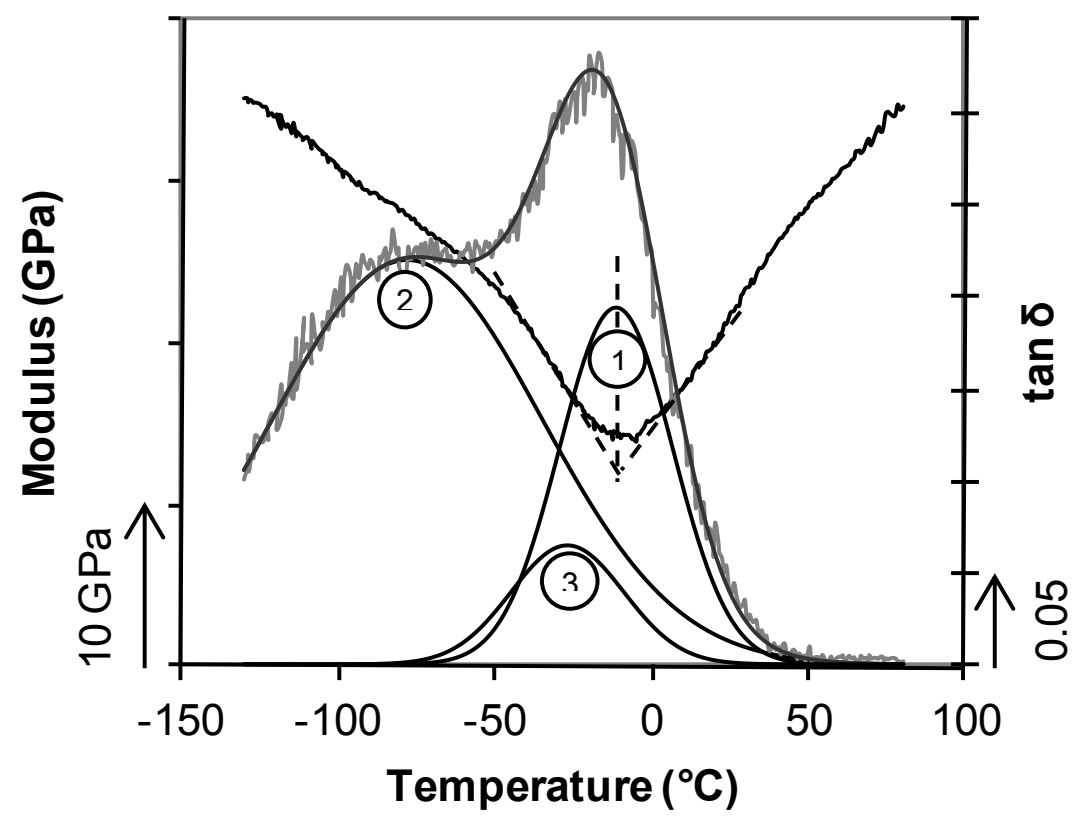

Fig. 8. Deconvolution of the damping curve by three Gaussian curves $\left(\sigma_{\max }=200 \mathrm{MPa}\right.$, cooling). 